\title{
Social Interaction With Agents and Avatars in Immersive Virtual Environments: A Survey
}

\author{
Christos Kyrlitsias and Despina Michael-Grigoriou * \\ GET Lab, Department of Multimedia and Graphic Arts, Cyprus University of Technology, Limassol, Cyprus
}

Immersive virtual reality technologies are used in a wide range of fields such as training, education, health, and research. Many of these applications include virtual humans that are classified into avatars and agents. An overview of the applications and the advantages of immersive virtual reality and virtual humans is presented in this survey, as well as the basic concepts and terminology. To be effective, many virtual reality applications require that the users perceive and react socially to the virtual humans in a realistic manner. Numerous studies show that people can react socially to virtual humans; however, this is not always the case. This survey provides an overview of the main findings regarding the factors affecting the social interaction with virtual humans within immersive virtual environments. Finally, this survey highlights the need for further research that can lead to a better understanding of human-virtual human interaction.

Daniel Thalmann

Swiss Federal Institute of Technology Lausanne, Switzerland

Reviewed by:

Esperanza Johnson, University of Castilla-La Mancha,

Spain

Jean-Luc Lugrin,

Julius Maximilian University of

Würzburg, Germany

*Correspondence:

Despina Michael-Grigoriou despina.grigoriou@cut.ac.cy

Specialty section:

This article was submitted to Virtual Reality and Human Behaviour,

a section of the journal

Frontiers in Virtual Reality

Received: 05 October 2021 Accepted: 10 December 2021

Published: 11 January 2022

Citation:

Kyrlitsias $C$ and Michael-Grigoriou D (2022) Social Interaction With Agents and Avatars in Immersive Virtual

Environments: A Survey.

Front. Virtual Real. 2:786665.

doi: 10.3389/frvir.2021.786665
Keywords: virtual reality, agents, avatars, social presence, social interaction

\section{INTRODUCTION}

Apart from the fact that virtual reality (VR) technologies can simulate environments and situations in a realistic and believable manner, they offer several advantages that make their use very beneficial in various fields. As a result, in the past decade, VR technologies are used in a wide range of applications. For example, social VR applications (McVeigh-Schultz et al., 2018) allow people to remotely meet, collaborate, and share (Li et al., 2019). Also, many of the most widely used and promising VR applications concern training simulations that are used as a training tool for pilots and drivers of various vehicles, dangerous jobs such as mine workers (Bellanca et al., 2019), and the military (Koźlak et al., 2013). A key advantage of using VR in these applications is that it provides realistic training conditions in a controlled and, therefore, much safer environment while significantly reducing the cost and increasing the efficiency of the training. Things that cannot be controlled in the physical world, such as the time of day, or are random, such as the weather conditions, in a virtual world are fully controllable. Moreover, VR offers the possibility of repeating scenarios and evaluating the learner's performance better. The introduction of VR in education can enhance learning outcomes (Merchant, Goetz, Cifuentes, Keeney-Kennicutt and Davis, 2014). VR increases the learner's motivation and involvement. VR allows students to experience, rather than just watch and listen, while promoting complex learning (Villena Taranilla et al., 2019). It gives students an opportunity to explore objects or events that are not accessible, such as the solar system, historical places, and events (Villena Taranilla et al., 2019; Kyrlitsias et al., 2020) or the inside of the human body (Parong and Mayer, 2018; Michael-Grigoriou, Yiannakou and Christofi, 2017). Also, VR can be beneficial for teacher training (Stavroulia et al., 2019). Immersive virtual reality technologies are used in the fields of health on the part of education and training as well as in 
various kinds of therapies. The use of simulators in medical education protects patients while offering students a way to develop their skills, knowledge, and confidence, as well as evaluating their performance (Lateef, 2010; Pottle, 2019). Virtual reality therapies (Wiederhold and Riva, 2019) are used in patients with various phobias such as fear of heights (Rothbaum et al., 1995; Seinfeld et al., 2016), claustrophobia (Christofi, and Michael-Grigoriou, 2016; Rahani et al., 2018), fear of public speaking (Nazligul et al., 2017; Takac et al., 2019), social anxiety (Chesham et al., 2018), posttraumatic stress (Botella, Serrano, Baños, and Garcia-Palacios, 2015), and depression (Falconer et al., 2016).

The above are just a few examples of applications of VR technologies in various fields, through which we can distinguish the advantages of this technology. To summarize, VR technologies can provide affordable, realistic, controlled, safe, interactive, and accessible experiences to the user. Below, the basic concepts related to virtual humans (VHs) and VR are presented along with the relevant references. Then, the theory and the main factors that affect social interactions with VHs are presented. Finally, the authors summarize and discuss the topic, and suggest future research directions on social interactions with VHs. The references listed in this survey were selected by the authors to better illustrate the relevant literature. No systematic approach was followed for this survey.

\section{VIRTUAL HUMANS}

Many of these applications described above require the inclusion of virtual representations of humans. The representations of humans in virtual environments are called VHs. We define a $\mathrm{VH}$ as a "perceivable digital representation" of a human (Bailenson and Blascovich, 2004). VHs are classified into avatars and agents (Bailenson and Blascovich, 2004; von der Pütten et al., 2010), depending on who directs their behavior. An avatar is a $\mathrm{VH}$ whose behaviors reflect those executed by a specific human being. On the other hand, an agent is a VH whose behaviors are determined by the computer algorithm. However, since today's technology is unable to reflect all human actions on avatars, the distinction between an agent and an avatar is not always clear (Bailenson and Blascovich, 2004). Various forms of communications (e.g., facial expressions, gaze behavior, tone of voice, or body language) that may not be tracked by the system and, therefore, not attributed to the avatar are omitted or alternatively rendered onto the VH. As a result, a $\mathrm{VH}$ usually constitutes a hybrid of an agent and an avatar. However, recent technological advances such as real-time body and facial expression tracking can provide affordable solutions so the behavioral resemblance of the user and the avatar can be extremely accurate. In the future, we expect to have photorealistic avatars whose voices, movements, facial expressions, and gaze are determined completely by the user in real time. Despite that, hybrid agent-avatars can be used to combine the advantages of both agent and avatar technologies (Roth, Latoschik, Vogeley and Bente, 2015). Additionally, unlike the physical world where there are clear boundaries between humans and nonhumans, there are not necessarily any visible differences between human-controlled and computer-controlled VHs (Nowak and Fox, 2018). It is up to the developer of the VR application to conceal or inform (or even mislead) the user whether a $\mathrm{VH}$ is an avatar or an agent. Therefore, in a shared virtual environment, the user may not know which of the VHs are agents and which are avatars.

\section{Avatars}

In immersive virtual environments (IVEs), an avatar is the (usually visual) representation of the user in a virtual world. An avatar is perceivable by the user and/or by the other users, in the case of multiuser virtual environments (Nowak and Fox, 2018) such as social VR applications (Gunkel et al., 2018; McVeigh-Schultz et al., 2018). In the case of the selfrepresentation, the users can observe their avatar from either a first-person or a third-person perspective (Gorisse, Christmann, Amato and Richir, 2017), whereas in some cases the use of avatars is implied or omitted. In projection-based VR systems (e.g., Cruz-Neiraet al., 1993; Roth, Waldow, Latoschik, Fuhrmann and Bente, 2017), no avatars are required for selfrepresentation since the users can observe their physical body. In head-mounted display (HMD)-based VR settings, users are unable to see their physical body. In these cases, an avatar can be used to provide the users with a virtual body, usually with a first-person perspective. The degree to which the users can control their avatars varies, depending on the capabilities of the VR system. Under some situations (Kilteniet al., 2012), a sense of ownership over the virtual body can emerge to the user, which is called the sense of embodiment. Studies (Slater and Sanchez-Vives, 2014) showed that people tend to alter their attitudes and behaviors to match the expectations that are implied by the attributes of their virtual body. This phenomenon is known as the Proteus effect (Yee et al., 2009).

\section{Agents}

With the constant advancement of technology in the fields of computer graphics, machine learning, and artificial intelligence (Petrović, 2018), virtual agents are becoming more and more realistic in both appearance and behavior. At the same time, the opportunities and the efficiency of their use increase.

In VR entertainment applications, such as videogames, we refer to VHs that are used as actors in the game environment as non-player characters (NPCs). They act in the game as hostile, friendly, or neutral characters to the player. Their behavior is most of the time scripted and limited to the level needed to support their role in the game. However, there are examples of NPCs that are able to interact in more complex ways with the player (Takahashi et al., 2018), such as expressing emotions (Li and Campbell, 2010), taking decisions autonomously (Xi and Smith, 2016), and acting independently. The NPCs are a crucial part of a VR game and can drastically impact the user's gaming experience (Petrović, 2018).

Using VR, agents can play the role of the audience in applications for practicing presentation skills and overcoming public-speaking anxiety. Individuals can practice their presentations or speeches in an immersive virtual environment 
that includes real-life conditions. Studies (Nazligul et al., 2017; Takac et al., 2019) have shown that these applications are found to be beneficial in treating social anxiety disorders. Also, the number and the behavior of an audience consisting of agents are highly flexible and customizable, allowing the gradation of the challenge level using different scenarios (Botella, Garcia-Palacios, Baños and Quero, 2009). In the same way, agents are used in the treatment of various types of phobias using VR. The virtual agents who, through the use of artificial intelligence, have the capability of engaging in humanlike conversations are referred to as conversational agents (Yildirim, 2021). In some examples, agents are used to help, guide, encourage, and motivate the patient, replacing the human therapist (Bălan et al., 2020), while sometimes replacing patients in training scenarios for doctors and therapists (Lok et al., 2006; Rizzo and Talbot, 2016), or motivating other patients (Najm et al., 2020). Agents are used as healthcare assistants (Kim et al., 2019) to support registered healthcare professionals in conducting clinical tasks and providing care to the patients. Also, a study (Lucas, Gratch, King and Morency, 2014) showed that VH-interviewers can increase willingness to disclose and elicit more honest responses in a clinical interview context. In educational VR applications, agents have a crucial role, either as teachers or students. Studies showed that using pedagogical (Johnson and Lester, 2018; Makransky et al., 2019) agents can improve students' learning experience in an educational VR environment, enhance their engagement, and improve their knowledge construction and performance (Grivokostopoulou et al., 2020). Also, agents can play the role of students in teacher training scenarios (Stavroulia et al., 2019).

These were just a few examples of how the recruitment of virtual agents can be beneficial in an unlimited range of applications. They can be used in combination with other technologies to replace humans in social tasks efficiently. To summarize, some of the advantages of the use of virtual agents are that they are always available, even for multiple instances at the same moment; affordable; fully customizable and flexible, in both appearance and behavior; and fully controllable.

\section{Hybrid Agents-Avatars}

While the addition of computer-controlled behavior in avatars is usually performed to cover the inability of the technology to mirror the user's behavior (Bailenson and Blascovich, 2004), hybrid agent-avatars can be used to modify or enhance the avatar-mediated communication in shared VEs (Roth et al., 2015). For example, a study (Beall, Bailenson, Loomis, Blascovich and Rex, 2003) showed the example that an avatar can be shown to maintain eye contact with more than one interactant at a time. A study by Oh, Bailenson, Krämer, and Li (2016) showed enhancing the smile that was tracked from the participant led to more positive communication outcomes. In another study (Roth, Mal, Purps, Kullmann and Latoschik, 2018), mimicry behavior was injected in an avatar-meditated interaction to enhance the interpersonal understanding and rapport between the interactants. Roth, Kullmann, Bente, Gall, and Latoschik (2018) altered the avatar's tracked gaze direction in selected occasions to induce a listening focus to the other user.

\section{THE USE OF IMMERSIVE VIRTUAL REALITY AND VIRTUAL HUMANS FOR RESEARCH}

We have previously referred to the benefits and possibilities that immersive virtual reality (IVR) technologies offer as well as to the solutions that these technologies provide in a wide range of fields. Besides that, researchers have come to realize early that IVR can be very useful as a research tool (Blascovich et al., 2002; Tarr and Warren, 2002; Foreman, 2009). In the last 2 decades, IVR technologies are used for the study of human behavior and cognition in the fields of psychology (Wilson and Soranzo, 2015; Pan and Hamilton, 2018) and neuroscience (Bohil et al., 2011; Parsons et al., 2017; Bell, Nicholas, Alvarez-Jimenez, Thompson and Valmaggia, 2020).

Additionally, studies replicated classic social experiments in using IVR and VHs, demonstrating social effects such as obedience (Slater et al., 2006; Neyret et al., 2020), conformity (Kyrlitsias and Michael-Grigoriou, 2018; Kyrlitsias et al., 2020), and social facilitation/inhibition (Hoyt et al., 2003).

IVR technologies not only can offer researchers solutions to address several methodological problems, but they also create new research possibilities that were not possible in the past.

With IVR technologies, researchers can achieve realistic and complex environments that simulate accurately the experimental scenario and, therefore, high mundane realism (the degree to which the materials and procedures involved in an experiment are similar to events that occur in the real world; Kelly, 2007). At the same time, IVR provides the capability to induce to the participant the illusion of presence and elicit realistic (similar to real-life) reactions (Slater, 2009), achieving high experimental realism (the extent to which situations created in experiments are real and impactful to participants; Kosloff, 2007). This applies also to experiments that include social interactions, through social presence, as subjective feelings, and behavioral and physiological reactions during human-VH interactions can be very similar to those shown during human-human interactions (Bombari, Schmid Mast, Canadas and Bachmann, 2015).

Consequently, VR offers the possibility to conduct experiments with high ecological validity ("the extent to which research findings would generalize to settings typical of everyday life"; Baumeister and Vohs, 2007, p. 276), something that in the past was very difficult and required a high amount of resources to be achieved. For example, in experiments studying social influence, actors trained to maintain the same verbal and nonverbal behavior across sessions were used as confederates (Asch, 1956; Milgram, 1963). These solutions not only lead to more expensive experimental scenarios but are also difficult to implement and can often affect the level of experimental control. And this is one of the main methodological problems for researchers, the tradeoff between ecological validity and experimental control (Blascovich et al., 2002; Kothgassner and Felnhofer, 2020). VR technologies can provide a high level of ecological validity as they can generate stimuli that approximate the complexity of a real-life situation while allowing the investigator for near-perfect experimental control (Bombari et al., 2015; Parsons, 2015). The high level of experimental 
control and the flexibility offered to the experimenter by VR technologies "enables the researcher to selectively manipulate variables that in naturalistic situations cannot be independently investigated" (Parsons, 2015, p. 7).

In addition, using VR makes replication of studies easier. According to Blascovich et al. (2002), in domains such as social neuroscience and psychology, one of the reasons for the lack of replications is the difficulty for a researcher to implement and use the exact methods and procedures of other investigators. VR technologies, however, enable researchers to conduct perfect (or at least near-perfect) replications (Bombari et al., 2015).

Finally, using VR, researchers can conduct experiments with scenarios that are impossible (e.g., Friedman et al., 2014) or unethical (e.g., Gonzalez-Franco et al., 2018; Neyret et al., 2020) to be tested in real life. This is possible because participants react to virtual characters and events as if they were real, and at the same time they remain aware that there are no real danger and consequences as a result of their actions (Pan and Hamilton, 2018). For example, perception and behavior in dangerous or threatening situations can be studied, without participants being exposed to real danger (Kinateder et al., 2015; McCall, Hildebrandt, Bornemann and Singer, 2015). Even though the main effort in research and development focuses on the best possible simulation of the real world, VR has the possibility of going beyond the limits of physical reality (Slater and SanchezVives, 2016). Rules that exist in the "real" world do not necessarily exist in a virtual world. The physical laws, the time continuity (Friedman et al., 2014), human body characteristics, and limits (Slater and Sanchez-Vives, 2014) are manipulatable by the researcher, creating new research opportunities. For example, in a recent study (Friedman et al., 2014), the participants were given the illusion of traveling back in time, having the ability to prevent a tragic event in which they were present.

Using VR, researchers are able to dramatically alter the participants' self-representation by inducing in them a sense of embodiment toward a virtual body with different characteristics. This ability created a wide range of opportunities for investigating the impact of self-representation on the individual's attitudes and behaviors (Maister, Slater, Sanchez-Vives and Tsakiris, 2015). Even if in experiments with such manipulations the ecological validity is typically low, researchers can investigate the interaction with different variables and expand the theoretical understanding of human cognition and behavior (Bombari et al., 2015). A study by Kilteni et al. (2013) showed that participants embodied in a dark-skinned, casually dressed, virtual body expressed significantly greater body movement in a task that required playing drums than participants embodied in a light-skinned, formally dressed, body. This result was attributed to the stereotype that a dark-skinned, casually dressed, body is expected to be more bodily expressive. Other studies (Maister, Sebanz, Knoblich and Tsakiris, 2013; Peck, Seinfeld, Aglioti and Slater, 2013) showed that embodiment in a dark-skinned body resulted in a reduction of the implicit racial bias toward dark-skinned people. Also, a study found that the impact on implicit racial bias remained even a week after the participants' embodiment experience (Banakou et al., 2016).
To summarize, VR technologies became a powerful tool for researchers and studying human behavior. They can provide a series of advantages, such as realistic and complex experimental scenarios with almost perfect experimental control of the environment and the VHs, allowing researchers to overcome methodological problems. Additionally, they create new research opportunities for testing scenarios that are difficult or even impossible to be conducted in real-life settings.

\section{IMMERSIVE VIRTUAL ENVIRONMENTS AND VIRTUAL HUMAN TECHNOLOGIES}

With VR we refer to the creation of simulated environments (i.e., IVEs) with the use of computer technology, software, and hardware. In contrast to traditional interfaces, VR not only displays the created environments to the users but also gives them the feeling that they are "inside" the environment. This is achieved by "careful integration of hardware and software systems, including multimedia development software, databases, computers, rendering engines, and user interfaces" (Blascovich et al., 2002, p. 107). Today, typical VR systems provide stereoscopic vision that is updated as a function of the user's head-tracking and directional audio (Slater and SanchezVives, 2016). It is also common for the VR systems to provide additional tracking technology (apart from the head) for the user's hands or even for the full body. An article by Slater and Sanchez-Vives (2016) presents an overview of the basic concepts and the technology of VR systems.

The applications described above are feasible due to the huge technological advances that have taken place in the last 2 decades. Nevertheless, the possibilities of the current technology are not unlimited, but on the contrary they include several limitations and disadvantages. Therefore, the ideal virtual reality, in which the experience offered can be compared to that of the real world, is far from the possibilities of today. Above that, the availability, the cost, and the physical and technical limitations and drawbacks of the current technology are creating additional limitations and tradeoffs on the quality of a virtual reality experience.

For example, the visual fidelity of and rendering quality of virtual environments (and VHs) are limited by the computational capability of the computer. Some techniques are used for the optimization of performance that usually sacrifice realism, such as precomputed illumination (i.e., lighting, shadows, and reflections) instead of real time illumination that is changing dynamically. Another limitation is that the display quality (resolution and refresh rate) of the current VR systems is quite limited even in the most sophisticated VR devices (i.e., HMDs), with the distinction of pixel still visible and distracting. Despite continuous advances in computing power, graphic representation, and display quality, the visual quality in VR is yet far from perfect.

Even more challenging than displaying visually plausible virtual environments and humans is the attempt to display environments and humans that are behaving and interacting with the user in a realistic way. The way that users in VR can interact with virtual objects is an ongoing challenge. Designing of 
VHs (i.e., agents) that behave and interact with the user in a realistic way is an even bigger challenge due to the complexity of human behavior. Using the current technology, as described in the previous section, agents can interact with the user, have a verbal conversation, or show nonverbal responses such as facial expressions and gestures. However, in these examples, each aspect of the agents' behavior and intelligence is limited to the functions implemented by the creators, usually to support the purpose of the application.

Regarding avatars, the accurate resample of human actions such as body movements, facial expressions, and eye movements on the virtual body is important for inducing the sense of body ownership, as well as for communication with other users in sheared immersive environments. There are many available methods that are used to transfer the users' body movements to the avatar. These methods use different technologies and vary in accuracy, cost, and convenience of use. Advanced motion tracking systems that are used for full-body motion tracking of the user provide very accurate resemblance of the users' body movement on the avatar with low latency; however, these systems are very expensive and require the users to wear a suit of trackers and time for calibration. For finger tracking, additional gloves are required. Head position and orientation is typically tracked by the HMD. Commercial VR systems typically include tracked controllers that in combination with an inverse kinematic technique can be used for approximating the pose of the arms. Similarly, using 2, 3, or more additional trackers (typically for the feet and the waist), a full-body motion approximation can be achieved. This method does not provide as accurate results as the advanced motion tracking systems; however, it is significantly more affordable and easier to set up and use. Alternatively, instead of using additional trackers for the legs, prerecorded walking animations are used for the leg movement. Another method of tracking the users' body is using depth camera devices. This method has the advantage of not requiring the user to wear or hold any equipment; however, the tracking quality is limited. Additionally, HMDs with a built-in eye tracker, as well as facial trackers, are commercially available, which can be used to track the user's eye movements and facial expressions (including lip motion while talking), respectively, and render them on the avatar.

Besides visual information, for creating realistic VR experiences, additional senses such as touch, smell, temperature, and even taste (Rubio-Tamayo, Gertrudix Barrio and García García, 2017), can include meaningful information in face-to-face interactions. Additionally, a crucial aspect for inducing a sense of embodiment over a virtual body (i.e., avatar) is the creation of the illusion that the virtual body is the source of the experience sensations (Kilteni et al., 2012), usually achieved using synchronous visuotactile or visuoproprioceptive stimulation. Successful embodiment can have an impact on social interactions with VHs (Ratan, Beyea, Li and Graciano, 2020). Researchers used several tricks to simulate the sense of touch to the participants, such as the experimenter touching the participant with a wand (Slater et al., 2009). Today a wide range of devices are commercially available (Perret and Vander Poorten, 2018), mainly haptic gloves, with different approaches and functions. However, providing realistic haptic feedback with easy-to-use equipment remains a challenge.

Other limitations and problems that are associated with VR technologies over time are still challenging and need to be addressed in the future. One of them is the physical discomfort or cybersickness (Davis et al., 2014) that may result from the use of HMDs and can have a negative impact on the user's experience in the VE (Weech et al., 2019) and, therefore, on the social interactions taking place in it. One way of dealing with the problem of cybersickness is improving the hardware, by increasing the refresh rate, improving headtracking quality, and reducing tracking and display delay (Chang et al., 2020). Cybersickness is also attributed to the content of the VR application. For that reason, it is very important to develop VR applications to avoid content that promotes cybersickness and include techniques that are proven to reduce cybersickness.

Another inhered problem of VR is the locomotion within the virtual environment (Cherni et al., 2020). Even with the current HMDs that include positional tracking and allow the user to walk physically, the walking area is restricted to the physical space. Another method of navigation in the virtual environment is using a joystick; however, this method is associated with cybersickness (Saredakis et al., 2020). For that reason, teleporting has become a popular way of navigation in VR. A new way of locomotion in VR is omnidirectional treadmill devices that allow the user to navigate with seminatural movements while staying in place. However, these devices are still expensive and not easy to use (Christofi et al., 2020).

\section{VIRTUAL REALITY CONCEPTS}

\section{Immersion}

The ability of the system to provide the user with an illusion of reality is called immersion and is defined as "the extent to which the computer displays are capable of delivering an inclusive, extensive, surrounding and vivid illusion of reality to the senses of a human participant" (Slater and Wilbur, 1997, p. 3). Consequently, immersion can be objectively assessed, based on technical parameters used to describe a system.

As mentioned above, VR systems are not designed only to display the virtual environment to users but also attempt to induce the feeling that they are "inside" the environment, and that is what makes VR special. However, the term VR is sometimes used to describe systems that do not have the technical capability to induce the user with the sense of being inside the virtual environment that is displayed by the system. The terms non-immersive $V R$ and desktop $V R$ are also used to describe these systems. In this article, the term VR is used to describe immersive VR systems.

\section{Presence}

The use of VR technologies in a wide range of fields and the use of VHs in many of these applications were discussed in the previous section. A crucial factor for the effectiveness of many of these applications is that the user perceives and responds to the events 
and situations taking place in the virtual environment as if they were real. Empirical studies have explored factors that contribute to realistic behavior in immersive virtual environments, while various theories have attempted to explain this phenomenon. Most of these theories are based on the concept of presence, the sense of "being" in the virtual environment, also referred to as telepresence or place illusion (Ijsselsteijn and Riva, 2003; Sanchez-Vives and Slater, 2005; Slater, 2009). Slater (2009) defines presence as "the strong illusion of being in a place in spite of the sure knowledge that you are not there" (p. 3551).

Although it is strongly related to immersion (Slater, 2003), presence is a subjective perception determined by how the person perceives and interprets stimuli, defined by characteristics of the VR system and the level of immersion (Ijsselsteijn and Riva, 2003).

Presence has been the main focus of both applied and academic work on VR as it is associated with the effectiveness of a VR experience. The greater the sense of the user's presence in the virtual environment, the more realistic (similar to the real world) their reactions and behaviors are and, in turn, the more successful the VR application is (Cummings and Bailenson, 2016).

\section{Social Presence}

As described above, VR is capable of inducing to the users a sense of presence, which is the feeling of being in the virtual environment. The greater the sense of the users' presence in the virtual world, the more realistic (similar to the real world) their reactions and behaviors are. However, the sense of "being there" is not enough for a realistic perception and reaction toward VHs (Lee, Jung, Kim and Kim, 2006). In virtual environments, where the user coexists with VHs, it is important that the user perceives the presence of the $\mathrm{VH}$ not only physically but also socially. Social presence (also referred to as co-presence) refers to the extent to which the user actively perceives a $\mathrm{VH}$ in a virtual environment and at the same time has the sense that the "other" perceives the presence of the user (Biocca, 1997; Oh et al., 2018). While presence describes the illusion of "being" in a virtual space that may include VHs, social presence refers to the experience of "being together" with a sentient social being, either an agent or an avatar (Biocca et al., 2003).

Social presence is important due to the impact it has on social influence (Blascovich, 2002) and is associated with a variety of positive communication outcomes (Oh et al., 2018). For example, the results of a study (Thellman, Silvervarg, Gulz and Ziemke, 2016) demonstrated the effect of social presence on social influence by VHs. Specifically, participants who reported a stronger social presence were more inclined to accept the VH's offer in an ultimatum game. The impact of social presence on social influence is demonstrated by other studies (e.g., Hoyt et al., 2003; Strojny, Dużmańska-Misiarczyk, Lipp and Strojny, 2020). Consequently, the greater the sense of the users' social presence for a $\mathrm{VH}$, the more realistic (similar to human-human and face-to-face) their social reactions are. This makes social presence a vital component for the realism and the effectiveness of social interactions between the user and VHs in VR environments. Also, studies (Schroeder et al., 2001;
Heldal et al., 2005; Guimarães et al., 2020) showed that the participant's sense of social presence to VHs was higher for immersive VR than a non-immersive platform. This finding indicates the advantage of VR over non-immersive technologies in simulating social interactions with VHs.

\section{SOCIAL INTERACTION WITH VIRTUAL HUMANS}

Numerous studies show that people react socially to VHs. While an individual interacts with an avatar (or believing that it is an avatar), social responses are expected because such an interaction is perceived to be a human-human interaction mediated by the technology (Nowak and Fox, 2018). But why do individuals respond socially even if they know (or believe) that they are interacting with an agent, directed by a computer? Several theories attempt to explain social effects in interactions with computers. Earlier theories suggested that individuals socially react to computers temporarily due to the novelty of the situation (Kiesler and Sproull, 1997) or due to human deficits such as ignorance (Barley, 1988). Another approach suggests that social reactions are oriented toward the programmer rather than the computer itself (Dennett, 1987). However, the above theories have not been adopted and have become obsolete. The prevailing theory (Nasset al., 1994; Nass and Moon, 2000), known as the computers are social actors (CASA) paradigm, supports that social responses to computers result neither from the users' belief that they are interacting with the programmer nor from ignorance. Instead, the CASA paradigm argues that people unconsciously react to computers in the same way as they do toward humans. This can be attributed to the fact that the human brain is developed to automatically respond to social cues to deal successfully with daily life (Reeves and Nass, 1996, p. 97).

\section{Evaluating Social Interactions With Virtual Humans}

Several methods are used in the literature for the evaluation of the quality of the interactions with VHs. A common method of evaluation of social interactions with VHs is through subjective measures. Specifically, using self-reported questionnaires with which the participants are asked to evaluate their experience after their exposure to an IVE using scales such as social presence (Bioccaet al., 2003; Bailenson, Blascovich, Beall and Loomis, 2003), self-reported copresence, perceived other's copresence (Nowak, and Biocca, 2003) the Quality of Interaction, and Social Meaning (Li et al., 2019), and other positive communication outcomes such as likability and credibility (Guadagno, Blascovich, Bailenson and McCall, 2007).

Behavioral objective measures are also used in evaluating social interactions with VHs. Using VR technologies is very convenient for recording several aspects of the participants' behavior, for example, using the built-in motion trackers of the HMD and the built-in eye trackers, and by recording the participants' actions and navigation within the virtual environment. Measures such as participants' gaze behavior (Roth 
et al., 2018; Kyrlitsias et al., 2020), interpersonal distance (Bailenson, Blascovich, Beall and Loomis, 2003; Roth et al., 2018), verbal behavior (von der Pütten et al., 2010; Oh et al., 2016), social influence (Kyrlitsias et al., 2020; Neyret et al., 2020; Dzardanova, Kasapakis, Gavalas and Sylaiou, 2021), mimicry (Hasleret al., 2017), persuasion (Guadagno et al., 2007), and others are used as indicators of the effectiveness and the quality of social interactions.

Physiological measures are also used to evaluate social interactions with VHs: heart rate (Garau, Slater, Pertaub and Razzaque, 2005; Lee, Kolkmeier, Heylen and Ijsselsteijn, 2021), electrodermal activity (Garau et al., 2005; Neyret et al., 2020), and electroencephalography (Neyret et al., 2020).

Also, to avoid possible biases from confounding variables such as personality traits and simulation sickness, they are measured and used as control variables (e.g., Roth et al., 2018).

\section{FACTORS AFFECTING SOCIAL INTERACTION WITH VIRTUAL HUMANS}

The benefits of recruiting VHs in a wide range of applications are reviewed in a previous section. The effectiveness of these applications usually requires that the user perceive and interact with VHs as if they were real humans. For that reason, investigation of the factors that enhance social presence and increase social influence with VHs has attracted great interest by the researchers. An overview of the main findings regarding the factors that affect the social interaction with $\mathrm{VHs}$ is reviewed in this section.

\section{Representation of the Virtual Humans}

The way that VHs look and behave varies between different VR applications. These variations are not only due to the different capabilities of the VR systems regarding graphical quality and the interactivity, and the effort and the skill of the creators of the VR applications to provide convincing VHs but also due to the nature and purpose of the VR application. This results in VHs with different levels of realism. Several studies were conducted to investigate the impact of the VHs' visual and behavioral realism on social interactions.

\section{Visual Realism}

While studies showed that the presence of a VH's visual representation leads to a higher level of social presence compared to the absence of any visual representation (e.g., voice only), the effect of VHs' visual (photographic and anthropomorphic) realism is not consistent (Oh et al., 2018). For example, a recent study (Zibrek et al., 2019) investigated the level of a VH's visual realism using three render styles: realistic, simple, and sketch styles. The results showed that the level of a VH's visual realism did not have an impact on the participants' sense of the social presence of the VH. The impact of visual realism on the participants' emotional response was attributed to the fact that realistic rendering of the VH's facial expressions was more perceivable than the less realistic rendering, which is not directly associated with the level of realism.

\section{Behavioral Realism}

In contrast with visual realism, the VH's behavioral realism consists of an important factor for social interactions and a powerful predictor of social presence (Oh et al., 2018). Behavioral realism refers to the extent to which a $\mathrm{VH}$ behaves in the way an actual person would behave. Several studies showed that increasing the VH's behavioral realism leads to a stronger sense of social presence, especially when the VH's behavior indicates awareness of the user's presence (e.g., mutual gaze) and provides interactivity. The interactivity of a VH's behavior is an important factor for creating social presence (Oh et al., 2018) as it gives the impression that the $\mathrm{VH}$ is aware of the user's presence and actions. For example, a study (von der Pütten et al., 2010) showed that participants felt higher levels of social presence and mutual awareness, and talked more when the $\mathrm{VH}$ showed feedback behavior (head nodding) than when the $\mathrm{VH}$ did not show any feedback behavior. Another study (Guadagno et al., 2007) showed that VHs with more realistic gaze behavior led to a higher sense of social presence. Additionally, male participants reported more attitude change after interacting with male-like VHs with behavioral realism compared with male-like VHs with lower behavioral realism. Another study (Pan, Gillies Slater, 2008) focused on the effects of a VH's blushing during an embarrassing situation on participants' reaction. Especially, the effects of no blushing, cheek blushing, and whole-face blushing were compared. The results of the study showed that the VH's whole-face blushing improved participants' degree of social presence, while participants in the cheek blushing condition tended to withdraw earlier from the VH's presentation. A study by Roth et al. (2016) showed no difference in the effectiveness in a verbal negotiation task between participants embodied in abstract avatars without gaze behavior and facial expressions in VR, compared with physical word setting. This result suggests that the absence of behavioral cues can partly be compensated.

Enhancing the VH's behavioral realism implies increased social channels (e.g., the inclusion of facial expressions or gaze behavior) that are simulating better the face-to-face interactions. A study by Roth et al. (2018) investigated the impact of nonrealistic (in the means of simulating face-to-face interactions) social cues (i.e., social augmentations), by visualizing eye contact with floating bubbles, joint attention with particles, and grouping by matching the color of the abstract box-shaped avatars. The results of the study showed that the augmentations had a positive impact on participants' sense of social presence as well as an influence on their behavior. This result suggests that increasing social cues is important for social interactions with VHs, despite if these cues are replicating face-to-face interactions or not. It is also revealing the potential of VR to enhance social interactions with additional social channels.

\section{The Uncanny Valley}

Additionally, the uncanny valley theory (Mori et al., 2012) that initially referred to humanoid robots but also applies to $\mathrm{VHs}$ suggests that the relation between a VH's realism and the perceiver's affinity for it is not linear. Instead, as VHs appear more human-like, they become more appealing up to a certain 
point. When a VH looks and moves to an almost life-like degree, but not yet as a human, it is perceived as creepy and unsettling. Only when the realism of a VH is fully convincing will it elicit positive responses. Consequently, this effect can have a negative impact on social interactions with VHs (Nowak and Fox, 2018). The results of a study (Groom et al., 2009) support the uncanny valley theory, as the $\mathrm{VH}$ received lower evaluations by the participants when exhibiting more realistic behavior (i.e., lip sync and body movement). The persuasiveness of the $\mathrm{VH}$ is not affected by the level of realism.

\section{Self-Representation}

Studies showed that the appearance of the user's avatar (i.e., selfrepresentation in the virtual environment) may have an impact on the social interactions with VHs (Ratan, Beyea, Li and Graciano, 2020). This effect is related to the sense of embodiment inside the virtual body (Kilteni et al., 2012), and the tendency of altering attitudes and behaviors to match the expectations that are implied by the attributes of their virtual body, named the Proteus effect (Yee et al., 2009; Slater and Sanchez-Vives, 2014). For example, a study by Yee and Bailenson (2007) showed that participants embodied in taller avatars were more confident in a negotiation task (the ultimatum game; Forsythe, Horowitz, Savin and Sefton, 1994) with an agent confederate.

\section{Agency}

Agency is the extent to which the user believes that a $\mathrm{VH}$ is controlled by another user (avatar) rather than a computer through an algorithm (agent). Blascovich (2002) defines agency as "the extent to which individuals perceive virtual others as representations of real persons" ( $p$. 130). When the user has the impression that a $\mathrm{VH}$ is controlled by another user, the level of agency is high. Instead, when the user believes that a $\mathrm{VH}$ is controlled by the computer, the level of agency is considered to be low. It is important to state that the level of agency describes the user's perception of the $\mathrm{VH}$ as an agent or an avatar, rather than the VH's actual state (Fox et al., 2015). Additionally, agency is a continuum, as individuals perceive a $\mathrm{VH}$ to be partially controlled by a human and the computer (Blascovich, 2002). It is important to note that the term agency is also used to describe the feeling of controlling one's own (virtual) body (Tsakiris et al., 2006), and the two definitions should not be confused.

The impact of agency on social interactions with VHs is not clear in the literature. According to the CASA theory, the responses to computers that exhibit human characteristics are mindless and automatic (Reeves and Nass, 1996; Nass and Moon, 2000), and therefore, people will respond socially to VHs regardless of the level of agency. On the contrary, the Threshold Model of Social Influence (Blascovich, 2002; Blascovich et al., 2002) argues that agency, along with behavioral realism, is a major factor that affects social presence.

According to the Threshold Model of Social Influence, an increase in agency and/or behavioral realism leads to an increase in social presence. If/when social presence meets a threshold value, social influences begin to operate. Specifically, when the user believes that the $\mathrm{VH}$ is controlled by the computer (low agency), the VH must behave very realistically in order for the social influence threshold to be met and social influence to occur. If the individual believes that the $\mathrm{VH}$ represents a real person (high agency), then behavioral realism does not need to be high to cause a social reaction. According to the authors, the location of the social influence threshold varies as a function of two moderating factors, which are interpersonal self-relevance and the response system. Interpersonal self-relevance is the importance of the interaction to the individual's sense of self. In a social interaction that requires a discussion of one's beliefs and attitudes (e.g., participating in a job interview), the interpersonal self-relevance is expected to be high. In social interactions that do not involve central or core aspects of an individual (e.g., making a small withdrawal from a bank), the interpersonal self-relevance is expected to be low. According to the model of social influence, when self-relevance is low, the threshold's slope is shallow, which means that lower behavioral realism is required for social influence to occur. Instead, in high self-relevance interactions, the slope is steep, and therefore, higher behavioral realism is required for the threshold to be crossed and social influence to occur. The second factor that moderates the social influence threshold is the level of the behavioral response system of interest. For low-level response systems such as unconscious reflexes, the threshold is lower compared to high-level response systems such as verbal communication. Therefore, a lower level of agency and behavioral realism is required for low-level, implicit, or automatic social responses than for high-level response systems involving purposeful and conscious actions.

Several studies explored the impact of agency on social interactions with VHs. The perceived agency was manipulated generally by introducing the $\mathrm{VH}$ as an agent or an avatar prior to the interaction. For example, a study by Guadagno, Swinth and Blascovich (2011) examined the social evaluations (i.e., empathy and positivity) for a virtual peer counselor, who was introduced as either an agent or an avatar. The VH had two levels of behavior (i.e., smile and not smile). The results showed that the VH's smile affected the social evaluations; however, the level of agency moderated this effect. Specifically, the social evaluations were enhanced by the smile behavior for participants in the low-agency condition but were degraded in the high-agency condition. Using two experiments, de Melo, Gratch and Carnevale (2014) examined the effect of the VH's emotional expressions on participants' behavior. The results of the first experiment showed that the participants collaborated more with the $\mathrm{VH}$ who exhibited collaborative instead of competing expressions in a social dilemma, and this effect was more intense in the highagency condition. In the second experiment, the participants who were led to believe that they were interacting with an avatar conceded more in a negotiation task when the VH showed angry expressions. Instead, in the low-agency condition, the participants conceded the same regardless of whether the $\mathrm{VH}$ showed neutral or angry emotions. The results of a study (Felnhofer et al., 2018) that examined social avoidance tendencies and prosocial behaviors toward VHs were contradictory regarding the impact of agency. While presence, 
social presence, social interaction anxiety, and stress were not affected by agency, participants in the avatar condition showed more social avoidance and prosocial behavior. The results of a study by von der Pütten et al. (2010) showed no effect of agency on participants' social behavior and evaluations.

As shown above, there are several examples in the literature aiming to compare the usage of agents versus avatars, with many studies proving that avatars affect the social behavior of participants to a greater extent than agents, whereas others demonstrated no significant difference between the two. A meta-analysis by Fox et al. (2015) showed that perceived avatars produced stronger responses than perceived agents. A systematic review (Oh et al., 2018) reported that approximately half of the studies surveyed showed an impact of agency on social presence, whereas in the remaining half of the studies the participants perceived similar levels of social presence regardless of the level of agency.

\section{Level of Immersion}

Regarding social presence, the level of immersion does not seem to be as crucial as it is for presence (Oh et al., 2018), although some studies (Schroeder et al., 2001; Heldal et al., 2005) showed that participants reported a stronger sense of social presence when using an immersive compared to a non-immersive platform. Also, a recent study (Bailey et al., 2019) showed that children in an IVR condition demonstrated greater social influence (compliance) from a virtual character than children in a non-immersive condition, suggesting that IVR may elicit differential cognitive and social responses compared to less immersive technologies.

\section{DISCUSSION AND FUTURE DIRECTIONS}

In this article, we presented the applications and the potential of IVR and VHs in a wide range of fields such as training, education, and health. Additionally, we presented the benefits of using IVR as a research tool on experimental research in fields such as cognitive and social neuroscience and psychology. This potential stems from the many advantages of VR over traditional media. However, to be effective, many of these applications require that the user react to the virtual stimuli in a realistic way. The ability of the VR technologies to immerse the user in a virtual environment, and therefore to react in a realistic manner to it (as the user was physically there), is considered straightforward due to the ability of VR to induce the illusion of "being" inside a virtual environment. This sense of being in the virtual environment is called presence and is associated with realistic reactions to the virtual stimuli.

In contrast, eliciting realistic reactions to social stimuli within virtual environments seems to be more complex, and a deeper understanding of the users' cognitive process is required to achieve them. While studies demonstrated realistic social reactions toward VHs within virtual environments, other studies failed to replicate social effects using VHs. To react realistically to a social situation, the user not only has to perceive the $\mathrm{VH}$ as it is physically present but also mentally present as it was a sentient human being. The extent to which the user actively perceives a $\mathrm{VH}$ in a virtual environment and at the same time has the sense that the "other" perceives the presence of the user is called social presence.

Several factors of the design of the VR applications and the virtual representations seem to impact the effectiveness of human-VH social interactions in terms of realistic reactions by the user. In this article, we listed several of these factors. Concerning the VH's representation, the literature suggests that visual realism (image fidelity) seems to be not so important in creating social presence and eliciting realistic social responses to the user. On the other hand, the literature suggests that the behavioral realism of a $\mathrm{VH}$ (the extent to which a $\mathrm{VH}$ behaves like a real human) is an important factor for social influence. Behavioral realism consists of many parameters such as verbal and nonverbal behavior (body movements and gestures, facial expressions, and gaze behavior), responsiveness, and interactivity with the environment and the user. Therefore, more research is needed in the direction of designing VHs' behavior to enhance their social potential.

As described in this article, the use of virtual agents offers many advantages over the use of avatars. The creation of agents that are perceived and treated by the users in a similar way as avatars is very important. The role of agency, the extent that the user believes that a $\mathrm{VH}$ is controlled by other humans rather than by the computer through an algorithm, is not clear in the literature. While studies supported the theory that users will respond socially to a $\mathrm{VH}$ only (or to a greater extent) when it is perceived as an agent (controlled by other users), other studies showed no impact of agency on social presence or social influence. According to the theory (Blascovich, 2002), the importance of agency depends on the type of interaction. Specifically, unconscious and automatic social reactions seem not to be affected by the level of agency (Nass and Moon, 2000), while interactions require more conscious social responses that are more likely to occur when the $\mathrm{VH}$ is perceived to be an avatar, controlled by another human, or an agent who behaves very realistically (Blascovich, 2002). Therefore, more studies are needed to investigate the impact of agency on social interactions with $\mathrm{VHs}$, taking into account the type of interaction. Additionally, according to Blascovich (2002), agents that are behaving realistic enough to exceed the threshold of social influence may overcome the limitation of agency and perceive the same way as agents, despite the fact that the user knows that they are interacting with an agent. This demonstrates the need of future research in the direction of creating agents with plausible, intelligent, and interactive behavior, which might be "the biggest challenge in social VR research" (Pan and Hamilton, 2018, pp. 410-411).

Another direction that is offered for future research is the impact of self-representation in social interactions in VR environments. The sense of embodiment is the perception of the virtual body by the participant as his biological body (Kilteni et al., 2012), which could be achieved by using real-time full-body motion tracking technology and by mapping the participants' movements to those of their virtual avatars. Studies (Slater and 
Sanchez-Vives, 2014) showed that people tend to alter their attitudes and behaviors to match the expectations that are implied by the attributes of their virtual body, including social behavior (Yee and Bailenson, 2007). We presume that there is a great scope for further research $(\mathrm{Mal}, 2020)$ on the impact of several aspects of self-representation (e.g., visual realism, body characteristics, gender, and age) in many forms of social interactions in VR.

Also, there is evidence that the level of immersion has an impact on social interaction with VHs; however, the literature is very limited. Further investigation is needed on whether more immersive systems can enhance the realism of social interactions with VHs.

Finally, the commercialization of social VR to the general audience in the form of entertainment and socialization may involve risks and unpleasant psychological and social consequences. An article by Slater et al. (2020) summarizes the potential negative implications of VR. Studies showed that the exposure to VR and especially virtual embodiment can lead to beneficial emotional, cognitive, and behavioral changes. However, the same techniques can be used to the opposite direction, leading to negative and undesired changes. Also, exposure to enjoyable environments and interactions, as well as the ability to create a desired self-representation, can create an individual preference of the virtual world over the real world, or even lead to prioritizing the virtual world. Studies also showed that VR and VHs influence the behavior and actions of an

\section{REFERENCES}

Asch, S. E. (1956). Studies of independence and Conformity: I. A Minority of One against a Unanimous Majority. Psychol. Monogr. Gen. Appl. 70 (9), 1-70. doi: $10.1037 / \mathrm{h} 0093718$

Bailenson, J., and Blascovich, J. (2004). "Avatars," in Encyclopedia of HumanComputer Interaction. Editor W. S. Bainbridge (Great Barrington, MA: Berkshire), 62-64.

Bailey, J. O., Bailenson, J. N., Obradović, J., and Aguiar, N. R. (2019). Virtual Reality's Effect on Children's Inhibitory Control, Social Compliance, and Sharing. J. Appl. Dev. Psychol. 64, 101052. doi:10.1016/j.appdev.2019.101052

Bălan, O., Cristea, Ș., Moise, G., Petrescu, L., Ivașcu, S., Moldoveanu, A., et al. (2020). "eTher - an Assistive Virtual Agent for Acrophobia Therapy in Virtual Reality," in International Conference on Human-Computer Interaction (Cham: Springer), 12-25. doi:10.1007/978-3-030-59990-4_2

Banakou, D., Hanumanthu, P. D., and Slater, M. (2016). Virtual Embodiment of white People in a Black Virtual Body Leads to a Sustained Reduction in Their Implicit Racial Bias. Front. Hum. Neurosci. 10, 601. doi:10.3389/fnhum.2016.00601

Barley, S. R. (1988). “The Social Construction of a Machine: Ritual, Superstition, Magical Thinking and Other Pragmatic Responses to Running a CT Scanner," in Knowledge and Practice in Medicine: Social, Cultural, and Historical Approaches. Editors M. Lock and D. Gordon (Hingham, MA: Reidel), 497-539. doi:10.1007/978-94-009-2725-4_19

Baumeister, R. F., and Vohs, K. D. (2007). "Ecological Validity," in Encyclopedia of Social Psychology (Thousand Oaks, CA: SAGE Publications, Inc), 1, 276. doi:10.4135/9781412956253.n167

Beall, A. C., Bailenson, J. N., Loomis, J., Blascovich, J., and Rex, C. S. (2003). "Nonzero-sum Gaze in Immersive Virtual Environments," in Proceedings of HCI International.

Bell, I. H., Nicholas, J., Alvarez-Jimenez, M., Thompson, A., and Valmaggia, L. (2020). Virtual Reality as a Clinical Tool in Mental Health Research and Practice. Dialogues Clin. Neurosci. 22 (2), 169-177. doi:10.31887/ DCNS.2020.22.2/lvalmaggia individual, with social effects such as persuasion (Guadagno et al., 2007), obedience (Neyret et al., 2020), and conformity (Kyrlitsias et al., 2020). However, in contrast with the real world, a virtual environment and its virtual occupants, agents and even avatars, are highly controllable by the administrator of the VR application. This gives great power to the administrator of such applications over the users' behavior. These are only some examples of the ethical concerns raised by the introduction of VR as a mass consumer product and demonstrate that ethics is a major challenge for VR.

To sum up, realistic social interactions with VHs are crucial for the effectiveness for many VR applications; however, it is not yet clear how to achieve them, and further research is required.

\section{AUTHOR CONTRIBUTIONS}

CK and DM-G have made a substantial, direct, and intellectual contribution to this work.

\section{FUNDING}

This work has been partially funded by ED-DESPINA MICHAIL-300155-310200-3319 budget of the Cyprus University of Technology.

Bellanca, J. L., Orr, T. J., Helfrich, W. J., Macdonald, B., Navoyski, J., and Demich, B. (2019). Developing a Virtual Reality Environment for Mining Research. Mining, Metall. Exploration 36 (4), 597-606. doi:10.1007/s42461-018-0046-2

Biocca, F., Harms, C., and Burgoon, J. K. (2003). Toward a More Robust Theory and Measure of Social Presence: Review and Suggested Criteria. Presence: Teleoperators \& Virtual Environments 12 (5), 456-480. doi:10.1162/ 105474603322761270

Biocca, F. (1997). The Cyborg's Dilemma: Progressive Embodiment in Virtual Environments [1]. J. computer-mediated Commun. 3 (2), JCMC324. doi:10.1111/j.1083-6101.1997.tb00070.x

Blascovich, J., Loomis, J., Beall, A. C., Swinth, K. R., Hoyt, C. L., and Bailenson, J. N. (2002). TARGET ARTICLE: Immersive Virtual Environment Technology as a Methodological Tool for Social Psychology. Psychol. Inq. 13 (2), 103-124. doi:10.1207/S15327965PLI1302_01

Blascovich, J. (2002). "Social Influence within Immersive Virtual Environments," in The Social Life of Avatars: Presence and Interaction in Shared Virtual Environments. Editor R. Schroeder (London: Springer), 127-145. doi:10.1007/978-1-4471-0277-910.1007/978-1-4471-0277-9_8

Bohil, C. J., Alicea, B., and Biocca, F. A. (2011). Virtual Reality in Neuroscience Research and Therapy. Nat. Rev. Neurosci. 12 (12), 752-762. doi:10.1038/ nrn3122

Bombari, D., Schmid Mast, M., Canadas, E., and Bachmann, M. (2015). Studying Social Interactions through Immersive Virtual Environment Technology: Virtues, Pitfalls, and Future Challenges. Front. Psychol. 6, 869. doi:10.3389/ fpsyg.2015.00869

Botella, C., Garcia-Palacios, A., Baños, R. M., and Quero, S. (2009). Cybertherapy: Advantages, Limitations, and Ethical Issues. PsychNology J. 7 (1), 77-100.

Botella, C., Serrano, B., baños, R., and García-Palacios, A. (2015). Virtual Reality Exposure-Based Therapy for the Treatment of post-traumatic Stress Disorder: a Review of its Efficacy, the Adequacy of the Treatment Protocol, and its Acceptability. Ndt 11, 2533. doi:10.2147/NDT.S89542

Chang, E., Kim, H. T., and Yoo, B. (2020). Virtual Reality Sickness: a Review of Causes and Measurements. Int. J. Human-Computer Interaction 36 (17), 1658-1682. doi:10.1080/10447318.2020.1778351 
Chesham, R. K., Malouff, J. M., and Schutte, N. S. (2018). Meta-analysis of the Efficacy of Virtual Reality Exposure Therapy for Social Anxiety. Behav. Change 35 (3), 152-166. doi:10.1017/bec.2018.15

Christofi, M., Michael-Grigoriou, D., and Kyrlitsias, C. (2020). A Virtual Reality Simulation of Drug Users' Everyday Life: The Effect of Supported Sensorimotor Contingencies on Empathy. Front. Psychol. 11, 1242. doi:10.3389/ fpsyg.2020.01242

Christofi, M., and Michael-Grigoriou, D. (2016). "Virtual Environments Design Assessment for the Treatment of Claustrophobia," in 2016 22nd International Conference on Virtual System \& Multimedia (VSMM), IEEE, 1-8. doi:10.1109/ VSMM.2016.7863215

Cruz-Neira, C., Sandin, D. J., and DeFanti, T. A. (1993). "Surround-screen Projection-Based Virtual Reality," in Proceedings Of the $20^{\text {th }}$ Annual Conference on Computer Graphics and Interactive Techniques, 135-142. doi:10.1145/166117.166134

Cummings, J. J., and Bailenson, J. N. (2016). How Immersive Is Enough? A MetaAnalysis of the Effect of Immersive Technology on User Presence. Media Psychol. 19 (2), 272-309. doi:10.1080/15213269.2015.1015740

Davis, S., Nesbitt, K., and Nalivaiko, E. (2014). "A Systematic Review of Cybersickness," in Proceedings of the 2014 Conference on Interactive Entertainment, 1-9. doi:10.1145/2677758.2677780

de Melo, C. M., Gratch, J., and Carnevale, P. J. (2015). Humans versus Computers: Impact of Emotion Expressions on People's Decision Making. IEEE Trans. Affective Comput. 6 (2), 127-136. doi:10.1109/TAFFC.2014.2332471

Dennett, D. C. (1987). The Intentional Stance. Cambridge, MA: MIT Press.

Dzardanova, E., Kasapakis, V., Gavalas, D., and Sylaiou, S. (2021). Virtual Reality as a Communication Medium: a Comparative Study of Forced Compliance in Virtual Reality versus Physical World. Virtual Reality, 1-21. doi:10.1007/ s10055-021-00564-9

Falconer, C. J., Rovira, A., King, J. A., Gilbert, P., Antley, A., Fearon, P., et al. (2016). Embodying Self-Compassion within Virtual Reality and its Effects on Patients with Depression. BJPsych open 2 (1), 74-80. doi:10.1192/bjpo.bp.115.002147

Felnhofer, A., Kafka, J. X., Hlavacs, H., Beutl, L., Kryspin-Exner, I., and Kothgassner, O. D. (2018). Meeting Others Virtually in a Day-To-Day Setting: Investigating Social Avoidance and Prosocial Behavior towards Avatars and Agents. Comput. Hum. Behav. 80, 399-406. doi:10.1016/ j.chb.2017.11.031

Felnhofer, A., Kothgassner, O. D., Beutl, L., Hlavacs, H., and Kryspin-Exner, I. (2012). Is Virtual Reality Made for Men Only? Exploring Gender Differences in the Sense of Presence. Proc. Int. Soc. presence Res., 103-112.

Foreman, N. (2009). Virtual Reality in Psychology. Themes Sci. Tech. Edu. 2 (1), 225-252.

Forsythe, R., Horowitz, J. L., Savin, N. E., and Sefton, M. (1994). Fairness in Simple Bargaining Experiments. Games Econ. Behav. 6 (3), 347-369. doi:10.1006/ game.1994.1021

Fox, J., Ahn, S. J., Janssen, J. H., Yeykelis, L., Segovia, K. Y., and Bailenson, J. N. (2015). Avatars versus Agents: a Meta-Analysis Quantifying the Effect of agency on Social Influence. Human-Computer Interaction 30 (5), 401-432. doi:10.1080/07370024.2014.921494

Friedman, D., Pizarro, R., Or-Berkers, K., Neyret, S. n., Pan, X., and Slater, M. (2014). A Method for Generating an Illusion of Backwards Time Travel Using Immersive Virtual Realityâ€"an Exploratory Study. Front. Psychol. 5, 943. doi:10.3389/fpsyg.2014.00943

Garau, M., Slater, M., Pertaub, D.-P., and Razzaque, S. (2005). The Responses of People to Virtual Humans in an Immersive Virtual Environment. Presence: Teleoperators \& Virtual Environments 14 (1), 104-116. doi:10.1162/ 1054746053890242

Gonzalez-Franco, M., Slater, M., Birney, M. E., Swapp, D., Haslam, S. A., and Reicher, S. D. (2018). Participant Concerns for the Learner in a Virtual Reality Replication of the Milgram Obedience Study. PloS one 13 (12), e0209704. doi:10.1371/journal.pone.0209704

Gorisse, G., Christmann, O., Amato, E. A., and Richir, S. (2017). First- and ThirdPerson Perspectives in Immersive Virtual Environments: Presence and Performance Analysis of Embodied Users. Front. Robot. AI 4, 33. doi:10.3389/frobt.2017.00033

Grivokostopoulou, F., Kovas, K., and Perikos, I. (2020). The Effectiveness of Embodied Pedagogical Agents and Their Impact on Students Learning in Virtual Worlds. Appl. Sci. 10 (5), 1739. doi:10.3390/app10051739
Groom, V., Nass, C., Chen, T., Nielsen, A., Scarborough, J. K., and Robles, E. (2009). Evaluating the Effects of Behavioral Realism in Embodied Agents. Int. J. Human-Computer Stud. 67 (10), 842-849. doi:10.1016/j.ijhcs.2009.07.001

Guadagno, R. E., Blascovich, J., Bailenson, J. N., and McCall, C. (2007). Virtual Humans and Persuasion: The Effects of agency and Behavioral Realism. Media Psychol. 10 (1), 1-22. doi:10.1080/15213260701300865

Guadagno, R. E., Swinth, K. R., and Blascovich, J. (2011). Social Evaluations of Embodied Agents and Avatars. Comput. Hum. Behav. 27 (6), 2380-2385. doi:10.1016/j.chb.2011.07.017

Guimarães, M., Prada, R., Santos, P. A., Dias, J., Jhala, A., and Mascarenhas, S. (2020). "The Impact of Virtual Reality in the Social Presence of a Virtual Agent," in Proceedings of the 20th ACM International Conference on Intelligent Virtual Agents, 1-8. doi:10.1145/3383652.3423879

Gunkel, S., Stokking, H., Prins, M., Niamut, O., Siahaan, E., and Cesar, P. (2018). "Experiencing Virtual Reality Together," in Proceedings of the 2018 ACM International Conference on Interactive Experiences for TV and Online Video, 233-238. doi:10.1145/3210825.3213566

Hasler, B. S., Spanlang, B., and Slater, M. (2017). Virtual Race Transformation Reverses Racial In-Group Bias. PloS one 12 (4), e0174965. doi:10.1371/ journal.pone.0174965

Heldal, I., Schroeder, R., Steed, A., Axelsson, A., Spante, M., and Widestrom, J. (2005). "Immersiveness and Symmetry in Copresent Scenarios," in IEEE Proceedings. VR 2005, IEEE, 171-178. doi:10.1109/VR.2005.1492771

Hoyt, C. L., Blascovich, J., and Swinth, K. R. (2003). Social Inhibition in Immersive Virtual Environments. Presence: Teleoperators \& Virtual Environments 12 (2), 183-195. doi:10.1162/105474603321640932

Ijsselsteijn, W., and Riva, G. (2003). "Being There: The Experience of Presence in Mediated Environments," in Being There: Concepts, Effects and Measurements of User Presence in Synthetic Environments. Editors G. Riva, F. Davide, and W. A. Ijsselsteijn (Amsterdam: IOS Press), 3-16.

Johnson, W. L., and Lester, J. C. (2018). Pedagogical Agents: Back to the Future. AIMag 39 (2), 33-44. doi:10.1609/aimag.v39i2.2793

Kelly, J. R. (2007). "Mundane Realism," in Encyclopedia of Social Psychology. Editors R. F. Baumeister and K. D. Vohs (Thousand Oaks, CA: SAGE Publications, Inc), 1, 599. doi:10.4135/9781412956253.n357

Kiesler, S., and Sproull, L. (1997). “"Social” Human-Computer Interaction,” in Human Values and the Design of Computer Technology. Editor B. Friedman (Stanford, CA: CSLI Publications), 191-199.

Kilteni, K., Bergstrom, I., and Slater, M. (2013). Drumming in Immersive Virtual Reality: the Body Shapes the Way We Play. IEEE Trans. Vis. Comput. Graphics 19 (4), 597-605. doi:10.1109/TVCG.2013.29

Kilteni, K., Groten, R., and Slater, M. (2012). The Sense of Embodiment in Virtual Reality. Presence: Teleoperators and Virtual Environments 21 (4), 373-387. doi:10.1162/PRES_a_00124

Kim, K., Norouzi, N., Losekamp, T., Bruder, G., Anderson, M., and Welch, G. (2019).Effects of Patient Care Assistant Embodiment and Computer Mediation on User Experience. In 2019 IEEE International Conference on Artificial Intelligence and Virtual Reality. IEEE Computer Society, 17-177. doi:10.1109/aivr46125.2019.00013

Kinateder, M., Gromer, D., Gast, P., Buld, S., Müller, M., Jost, M., et al. (2015). The Effect of Dangerous Goods Transporters on hazard Perception and Evacuation Behavior - A Virtual Reality experiment on Tunnel Emergencies. Fire Saf. J. 78, 24-30. doi:10.1016/j.firesaf.2015.07.002

Kosloff, S. (2007). "Experimental Realism," in Encyclopedia of Social Psychology. Editors R. F. Baumeister and K. D. Vohs (Thousand Oaks, CA: SAGE Publications, Inc), 1, 329-330. doi:10.4135/9781412956253.n202

Kothgassner, O. D., and Felnhofer, A. (2020). Does Virtual Reality Help to Cut the Gordian Knot between Ecological Validity and Experimental Control? Ann. Int. Commun. Assoc. 44 (3), 210-218. doi:10.1080/ 23808985.2020.1792790

Koźlak, M., Kurzeja, A., and Nawrat, A. (2013). "Virtual Reality Technology for Military and Industry Training Programs," in Vision Based Systems for UAV Applications (Heidelberg: Springer), 327-334. doi:10.1007/978-3-319. 00369-6_21

Kyrlitsias, C., Christofi, M., Michael-Grigoriou, D., Banakou, D., and Ioannou, A. (2020). A Virtual Tour of a Hardly Accessible Archaeological Site: The Effect of Immersive Virtual Reality on User Experience, Learning and Attitude Change. Front. Comput. Sci. 2, 23. doi:10.3389/fcomp.2020.00023 
Kyrlitsias, C., and Michael-Grigoriou, D. (2018). Asch Conformity experiment Using Immersive Virtual Reality. Comput. Anim. Virtual Worlds 29 (5), e1804. doi:10.1002/cav.1804

Kyrlitsias, C., Michael-Grigoriou, D., Banakou, D., and Christofi, M. (2020). Social Conformity in Immersive Virtual Environments: The Impact of Agents' Gaze Behavior. Front. Psychol. 11, 2254. doi:10.3389/fpsyg.2020.02254

Lateef, F. (2010). Simulation-based Learning: Just like the Real Thing. J. Emerg. Trauma Shock 3 (4), 348. doi:10.4103/0974-2700.70743

Lee, K. M., Jung, Y., Kim, J., and Kim, S. R. (2006). Are Physically Embodied Social Agents Better Than Disembodied Social Agents?: The Effects of Physical Embodiment, Tactile Interaction, and People's Loneliness in Human-Robot Interaction. Int. J. human-computer Stud. 64 (10), 962-973. doi:10.1016/ j.ijhcs.2006.05.002

Lee, M., Kolkmeier, J., Heylen, D., and Ijsselsteijn, W. (2021). Who Makes Your Heart Beat? what Makes You Sweat? Social Conflict in Virtual Reality for Educators. Front. Psychol. 12. doi:10.3389/fpsyg.2021.628246

Li, J., Kong, Y., Röggla, T., De Simone, F., Ananthanarayan, S., De Ridder, H., et al. (2019). "Measuring and Understanding Photo Sharing Experiences in Social Virtual Reality," in Proceedings of the 2019 CHI Conference on Human Factors in Computing Systems, 1-14. doi:10.1145/3290605.3300897

Li, L., and Campbell, J. (2010). Emotion Modeling and Interaction of NPCS in Virtual Simulation and Games. Ijvr 9 (4), 1-6. doi:10.20870/IJVR.2010.9.4.2784

Lok, B., Ferdig, R. E., Raij, A., Johnsen, K., Dickerson, R., Coutts, J., Stevens, A., and Lind, D. S. (2006). Applying Virtual Reality in Medical Communication Education: Current Findings and Potential Teaching and Learning Benefits of Immersive Virtual Patients. Virtual Reality 10 (3-4), 185-195. doi:10.1007/ s10055-006-0037-3

Lucas, G. M., Gratch, J., King, A., and Morency, L.-P. (2014). It's Only a Computer: Virtual Humans Increase Willingness to Disclose. Comput. Hum. Behav. 37, 94-100. doi:10.1016/j.chb.2014.04.043

Maister, L., Sebanz, N., Knoblich, G., and Tsakiris, M. (2013). Experiencing Ownership over a Dark-Skinned Body Reduces Implicit Racial Bias. Cognition 128 (2), 170-178. doi:10.1016/j.cognition.2013.04.002

Maister, L., Slater, M., Sanchez-Vives, M. V., and Tsakiris, M. (2015). Changing Bodies Changes Minds: Owning Another Body Affects Social Cognition. Trends Cognitive Sciences 19 (1), 6-12. doi:10.1016/j.tics.2014.11.001

Makransky, G., Wismer, P., and Mayer, R. E. (2019). A Gender Matching Effect in Learning with Pedagogical Agents in an Immersive Virtual Reality Science Simulation. J. Comput. Assist. Learn. 35 (3), 349-358. doi:10.1111/jcal.12335

Mal, D. (2020). "[DC] the Impact of Social Interactions on an Embodied Individual's Self-Perception in Virtual Environments," in 2020 IEEE Conference on Virtual Reality and 3D User Interfaces Abstracts and Workshops (VRW), 545-546. doi:10.1109/VRW50115.2020.00124IEEE

McCall, C., Hildebrandt, L. K., Bornemann, B., and Singer, T. (2015). Physiophenomenology in Retrospect: Memory Reliably Reflects Physiological Arousal during a Prior Threatening Experience. Conscious. Cogn. 38, 60-70. doi:10.1016/j.concog.2015.09.011

McVeigh-Schultz, J., Márquez Segura, E., Merrill, N., and Isbister, K. (2018). "What's it Mean to "Be Social" in VR? Proceedings of the 2018 ACM Conference Companion Publication on Designing Interactive Systems, 289-294. doi:10.1145/3197391.3205451

Merchant, Z., Goetz, E. T., Cifuentes, L., Keeney-Kennicutt, W., and Davis, T. J. (2014). Effectiveness of Virtual Reality-Based Instruction on Students' Learning Outcomes in K-12 and Higher Education: A Meta-Analysis. Comput. Edu. 70, 29-40. doi:10.1016/j.compedu.2013.07.033

Milgram, S. (1963). Behavioral Study of Obedience. J. abnormal Soc. Psychol. 67 (4), 371-378. doi:10.1037/h0040525

Mori, M., MacDorman, K., and Kageki, N. (2012). The Uncanny valley [from the Field]. IEEE Robot. Automat. Mag. 19 (2), 98-100. doi:10.1109/ MRA.2012.2192811

Najm, A., Michael-Grigoriou, D., Kyrlitsias, C., Christofi, M., Hadjipanayi, C., and Sokratous, D. (2020). "A Virtual Reality Adaptive Exergame for the Enhancement of Physical Rehabilitation Using Social Facilitation," in ICAT-EGVE 2020 - International Conference on Artificial Reality and Telexistence and Eurographics Symposium on Virtual Environments Posters and Demos (Geneva: The Eurographics Association). doi:10.2312/ egve. 20201269
Nass, C., and Moon, Y. (2000). Machines and Mindlessness: Social Responses to Computers. J. Soc. Isssues 56 (1), 81-103. doi:10.1111/0022-4537.00153

Nass, C., Steuer, J., and Tauber, E. R. (1994). "Computers Are Social Actors," in Proceedings of the SIGCHI Conference on Human Factors in Computing Systems, 72-78. doi:10.1145/191666.191703

Nazligul, M. D., Yilmaz, M., Gulec, U., Gozcu, M. A., O'Connor, R. V., and Clarke, P. M. (2017). "Overcoming Public Speaking Anxiety of Software Engineers Using Virtual Reality Exposure Therapy," in European Conference on Software Process Improvement (Cham: Springer), 191-202. doi:10.1007/978-3-31964218-5_15

Neyret, S., Navarro, X., Beacco, A., Oliva, R., Bourdin, P., Valenzuela, J., et al. (2020). An Embodied Perspective as a Victim of Sexual Harassment in Virtual Reality Reduces Action Conformity in a Later Milgram Obedience Scenario. Sci. Rep. 10 (1), 1-18. doi:10.1038/s41598-020-62932-w

Nowak, K. L., and Biocca, F. (2003). The Effect of the Agency and Anthropomorphism on Users' Sense of Telepresence, Copresence, and Social Presence in Virtual Environments. Presence: Teleoperators \& Virtual Environments 12 (5), 481-494. doi:10.1162/105474603322761289

Nowak, K. L., Fox, J., and Fox, J. (2018). Avatars and Computer-Mediated Communication: A Review of the Definitions, Uses, and Effects of Digital Representations on Communication. Rcr 6, 30-53. doi:10.12840/issn.22554165.2018.06.01.015

Oh, C. S., Bailenson, J. N., and Welch, G. F. (2018). A Systematic Review of Social Presence: Definition, Antecedents, and Implications. Front. Robot. AI 5, 114. doi:10.3389/frobt.2018.00114

Oh, S. Y., Bailenson, J., Krämer, N., and Li, B. (2016). Let the Avatar Brighten Your Smile: Effects of Enhancing Facial Expressions in Virtual Environments. PloS one 11 (9), e0161794. doi:10.1371/journal.pone.0161794

Pan, X., Gillies, M., and Slater, M. (2008). "The Impact of Avatar Blushing on the Duration of Interaction between a Real and Virtual Person," in Presence 2008: The $11^{\text {th }}$ Annual International Workshop On Presence, 100-106.

Pan, X., and Hamilton, A. F. d. C. (2018). Why and How to Use Virtual Reality to Study Human Social Interaction: The Challenges of Exploring a New Research Landscape. Br. J. Psychol. 109 (3), 395-417. doi:10.1111/bjop.12290

Parong, J., and Mayer, R. E. (2018). Learning Science in Immersive Virtual Reality. J. Educ. Psychol. 110 (6), 785-797. doi:10.1037/edu0000241

Parsons, T. D. (2015). Virtual Reality for Enhanced Ecological Validity and Experimental Control in the Clinical, Affective and Social Neurosciences. Front. Hum. Neurosci. 9, 660. doi:10.3389/fnhum.2015.00660

Parsons, T., Gaggioli, A., and Riva, G. (2017). Virtual Reality for Research in Social Neuroscience. Brain Sci. 7 (4), 42. doi:10.3390/brainsci7040042

Peck, T. C., Seinfeld, S., Aglioti, S. M., and Slater, M. (2013). Putting Yourself in the Skin of a Black Avatar Reduces Implicit Racial Bias. Conscious. Cogn. 22 (3), 779-787. doi:10.1016/j.concog.2013.04.016

Perret, J., and Vander Poorten, E. (2018). "Touching Virtual Reality: a Review of Haptic Gloves," in ACTUATOR 2018; 16th International Conference on New Actuators (Bremen: VDE), 1-5.

Petrovic, V. M. (2018). Artificial Intelligence and Virtual Worlds - toward HumanLevel AI Agents. IEEE Access 6, 39976-39988. doi:10.1109/ ACCESS.2018.2855970

Pottle, J. (2019). Virtual Reality and the Transformation of Medical Education. Future Healthc. J. 6 (3), 181-185. doi:10.7861/fhj.2019-0036

Ratan, R., Beyea, D., Li, B. J., and Graciano, L. (2020). Avatar Characteristics Induce Users' Behavioral Conformity with Small-To-Medium Effect Sizes: a MetaAnalysis of the proteus Effect. Media Psychol. 23 (5), 651-675. doi:10.1080/ 15213269.2019 .1623698

Reeves, B., and Nass, C. (1996). The media Equation: How People Treat Computers, Television, and New media like Real People and Places. New York: Cambridge University Press.

Rizzo, A., and Talbot, T. (2016). Virtual Reality Standardized Patients for Clinical Training. Educ. Pract., 255-272. doi:10.1002/9781118952788.ch18

Roth, D., Klelnbeck, C., Feigl, T., Mutschler, C., and Latoschik, M. E. (2018).Beyond Replication: Augmenting Social Behaviors in Multi-User Virtual Realities. In IEEE Conference on Virtual Reality and 3D User Interfaces (VR). IEEE, 215-222. doi:10.1109/VR.2018.8447550

Roth, D., Kullmann, P., Bente, G., Gall, D., and Latoschik, M. E. (2018).Effects of Hybrid and Synthetic Social Gaze in Avatar-Mediated Interactions. In 2018 
IEEE International Symposium on Mixed and Augmented Reality Adjunct (ISMAR-Adjunct). IEEE, 103-108. doi:10.1109/ISMAR-Adjunct.2018.00044

Roth, D., Latoschik, M. E., Vogeley, K., and Bente, G. (2015). Hybrid Avatar-Agent Technology - A Conceptual Step towards Mediated "Social" Virtual Reality and its Respective Challenges. I-com 14 (2), 107-114. doi:10.1515/icom-2015-0030

Roth, D., Lugrin, J.-L., Galakhov, D., Hofmann, A., Bente, G., Latoschik, M. E., et al. (2016). Avatar Realism and Social Interaction Quality in Virtual Reality. IEEE Virtual Reality, 277-278. doi:10.1109/VR.2016.7504761

Roth, D., Mal, D., Purps, C. F., Kullmann, P., and Latoschik, M. E. (2018). "Injecting Nonverbal Mimicry with Hybrid Avatar-Agent Technologies," in Proceedings of the Symposium on Spatial User Interaction, 69-73. doi:10.1145/ 3267782.3267791

Roth, D., Waldow, K., Latoschik, M. E., Fuhrmann, A., and Bente, G. (2017). Socially Immersive Avatar-Based Communication. IEEE Virtual Reality, 259-260.

Rothbaum, B. O., Hodges, L. F., Kooper, R., Opdyke, D., Williford, J. S., and North, M. (1995). Virtual Reality Graded Exposure in the Treatment of Acrophobia: A Case Report. Behav. Ther. 26 (3), 547-554. doi:10.1016/S0005-7894(05)80100-5

Rubio-Tamayo, J., Gertrudix Barrio, M., and García García, F. (2017). Immersive Environments and Virtual Reality: Systematic Review and Advances in Communication, Interaction and Simulation. Mti 1 (4), 21. doi:10.3390/ mti1040021

Sanchez-Vives, M. V., and Slater, M. (2005). From Presence to Consciousness through Virtual Reality. Nat. Rev. Neurosci. 6 (4), 332-339. doi:10.1038/ nrn1651

Saredakis, D., Szpak, A., Birckhead, B., Keage, H. A. D., Rizzo, A., and Loetscher, T. (2020). Factors Associated with Virtual Reality Sickness in Head-Mounted Displays: a Systematic Review and Meta-Analysis. Front. Hum. Neurosci. 14, 96. doi:10.3389/fnhum.2020.00096

Schroeder, R., Steed, A., Axelsson, A.-S., Heldal, I., Abelin, Å., Wideström, J., et al. (2001). Collaborating in Networked Immersive Spaces: as Good as Being There Together? Comput. Graphics 25 (5), 781-788. doi:10.1016/S0097-8493(01) 00120-0

Seinfeld, S., Bergstrom, I., Pomes, A., Arroyo-Palacios, J., Vico, F., Slater, M., et al. (2016). Influence of Music on Anxiety Induced by Fear of Heights in Virtual Reality. Front. Psychol. 6, 1969. doi:10.3389/fpsyg.2015.01969

Slater, M. (2003). A Note on Presence Terminology. Presence-connect 3 (3), 1-5.

Slater, M., Antley, A., Davison, A., Swapp, D., Guger, C., Barker, C., et al. (2006). A Virtual Reprise of the Stanley Milgram Obedience Experiments. PloS one 1 (1), e39. doi:10.1371/journal.pone.0000039

Slater, M., Gonzalez-Liencres, C., Haggard, P., Vinkers, C., Gregory-Clarke, R., Jelley, S., et al. (2020). The Ethics of Realism in Virtual and Augmented Reality. Front. Virtual Real. 1, 1. doi:10.3389/frvir.2020.00001

Slater, M., Pérez Marcos, D., Ehrsson, H., and Sanchez-Vives, M. V. (2009). Inducing Illusory Ownership of a Virtual Body. Front. Neurosci. 3, 214-220. doi:10.3389/neuro.01.029.2009

Slater, M. (2009). Place Illusion and Plausibility Can lead to Realistic Behaviour in Immersive Virtual Environments. Phil. Trans. R. Soc. B 364 (1535), 3549-3557. doi:10.1098/rstb.2009.0138

Slater, M., and Sanchez-Vives, M. V. (2016). Enhancing Our Lives with Immersive Virtual Reality. Front. Robot. AI 3, 74 . doi:10.3389/ frobt.2016.00074

Slater, M., and Sanchez-Vives, M. V. (2014). Transcending the Self in Immersive Virtual Reality. Computer 47 (7), 24-30. doi:10.1109/MC.2014.198

Slater, M., and Wilbur, S. (1997). A Framework for Immersive Virtual Environments (FIVE): Speculations on the Role of Presence in Virtual Environments. Presence: Teleoperators \& Virtual Environments 6 (6), 603-616. doi:10.1162/pres.1997.6.6.603

Stavroulia, K. E., Christofi, M., Baka, E., Michael-Grigoriou, D., MagnenatThalmann, N., and Lanitis, A. (2019). Assessing the Emotional Impact of Virtual Reality-Based Teacher Training. Ijilt 36, 192-217. doi:10.1108/IJILT11-2018-0127

Strojny, P. M., Dużmańska-Misiarczyk, N., Lipp, N., and Strojny, A. (2020). Moderators of Social Facilitation Effect in Virtual Reality: Co-presence and Realism of Virtual Agents. Front. Psychol. 11, 1252. doi:10.3389/ fpsyg.2020.01252
Takac, M., Collett, J., Blom, K. J., Conduit, R., Rehm, I., and De Foe, A. (2019). Public Speaking Anxiety Decreases within Repeated Virtual Reality Training Sessions. Plos one 14 (5), e0216288. doi:10.1371/ journal.pone. 0216288

Takahashi, T., Tanaka, K., and Oka, N. (2018). "Adaptive Mixed-Initiative Dialog Motivates a Game Player to Talk with an NPC," in Proceedings of the 6th International Conference on Human-Agent Interaction, 153-160. doi:10.1145/ 3284432.3284436

Tarr, M. J., and Warren, W. H. (2002). Virtual Reality in Behavioral Neuroscience and beyond. Nat. Neurosci. 5 (11), 1089-1092. doi:10.1038/nn948

Tsakiris, M., Prabhu, G., and Haggard, P. (2006). Having a Body versus Moving Your Body: How agency Structures Body-Ownership. Conscious. Cogn. 15 (2), 423-432. doi:10.1016/j.concog.2005.09.004

Vard, A., Rahani, V., and Najafi, M. (2018). Claustrophobia Game: Design and Development of a New Virtual Reality Game for Treatment of Claustrophobia. J. Med. Signals Sens 8 (4), 231. doi:10.4103/jmss.JMSS_27_18

Villena Taranilla, R., Cózar-Gutiérrez, R., González-Calero, J. A., and López Cirugeda, I. (2019). Strolling through a City of the Roman Empire: an Analysis of the Potential of Virtual Reality to Teach History in Primary Education. Interactive Learn. Environments, 1-11. doi:10.1080/ 10494820.2019.1674886

von der Pütten, A. M., Krämer, N. C., Gratch, J., and Kang, S.-H. (2010). "It Doesn't Matter what You Are!" Explaining Social Effects of Agents and Avatars. Comput. Hum. Behav. 26, 1641-1650. doi:10.1016/j.chb.2010.06.012

Weech, S., Kenny, S., and Barnett-Cowan, M. (2019). Presence and Cybersickness in Virtual Reality Are Negatively Related: a Review. Front. Psychol. 10, 158. doi:10.3389/fpsyg.2019.00158

Wiederhold, B. K., and Riva, G. (2019). Virtual Reality Therapy: Emerging Topics and Future Challenges. Cyberpsychology, Behav. Soc. Networking 22 (1), 3-6. doi:10.1089/cyber.2018.29136.bkw

Wilson, C. J., and Soranzo, A. (20152015). The Use of Virtual Reality in Psychology: a Case Study in Visual Perception. Comput. Math. Methods Med. 2015, 1-7. doi:10.1155/2015/151702

Xi, M., and Smith, S. P. (2016).Supporting Path Switching for Non-player Characters in a Virtual Environment. In 2016 IEEE Virtual Reality (VR). IEEE, 315-316. doi:10.1109/VR.2016.7504780

Yee, N., Bailenson, J. N., and Ducheneaut, N. (2009). The Proteus Effect. Commun. Res. $\quad 36 \quad$ (2), 285-312. doi:10.1177/2F009365020833025410.1177/ 0093650208330254

Yee, N., and Bailenson, J. (2007). The Proteus Effect: The Effect of Transformed Self-Representation on Behavior. Hum. Comm Res 33 (3), 271-290. doi:10.1111/j.1468-2958.2007.00299.x

Yildirim, C. (2021).An Immersive Model of User Trust in Conversational Agents in Virtual Reality. In 2021 Third International Conference on Transdisciplinary AI (TransAI). IEEE, 17-18. doi:10.1109/TransAI51903.2021.00011

Zibrek, K., Martin, S., and McDonnell, R. (2019). Is Photorealism Important for Perception of Expressive Virtual Humans in Virtual Reality? ACM Trans. Appl. Percept. 16 (3), 1-19. doi:10.1145/3349609

Conflict of Interest: The authors declare that the research was conducted in the absence of any commercial or financial relationships that could be construed as a potential conflict of interest.

Publisher's Note: All claims expressed in this article are solely those of the authors and do not necessarily represent those of their affiliated organizations, or those of the publisher, the editors, and the reviewers. Any product that may be evaluated in this article, or claim that may be made by its manufacturer, is not guaranteed or endorsed by the publisher.

Copyright (๑) 2022 Kyrlitsias and Michael-Grigoriou. This is an open-access article distributed under the terms of the Creative Commons Attribution License (CC BY). The use, distribution or reproduction in other forums is permitted, provided the original author(s) and the copyright owner(s) are credited and that the original publication in this journal is cited, in accordance with accepted academic practice. No use, distribution or reproduction is permitted which does not comply with these terms. 